\title{
Neuralgia due to iliohypogastric nerve injury after inguinal hernioplasty: a case report
}

\author{
Kamleshsingh Shadhu', Dadhija Ramlagun ${ }^{\dagger}$, Simeng Chen and Lijia Liu*
}

\begin{abstract}
Background: Neuralgia due to iliohypogastric nerve entrapment from sutures and mesh after inguinal hernioplasty is a rare entity in clinic. Its' awareness and management remain a clinical challenge.

Case presentation: We report a case of 54-year-old male who presented with post-operative pain after 1 month and sensory disturbances of the right lower limb. He underwent partial neurectomy and during the surgery it was found that there was injury to iliohypogastric nerve due to entrapment from sutures and mesh.

Conclusion: We hope to strengthen awareness about the importance of the identification of iliohypogastric nerve during inguinal hernioplasty.
\end{abstract}

Keywords: Neuralgia, lliohypogastric nerve entrapment, Sensory disturbances, Partial neurectomy

\section{Background}

Postoperative pain after surgery of the right lower abdomen and inguinal region is an underestimated problem [1]. About $11 \%$ of all patients undergoing an inguinal hernioplasty will develop discomfort $[2,3]$. The main cause of inguinal pain is injury or irritation to the following nerves: ilioinguinal, iliohypogastric and genital branch of genitofemoral nerve [4]. Mechanical or thermal injury during surgical dissection and repair, nerve entrapment from sutures, staples, mesh, and adhesions or injuries related to the inflammatory response to prosthetic mesh material, are factors contributing to nerve injury $[5,6]$. Nerve damage incurred during surgery can cause acute pain just after the surgery. Sensory disturbances are frequently seen in these patients and it appears to be the most common aetiology [7]. The distribution area of the affected nerve is usually painful. The ilioinguinal nerve is known as to be the most common neural pain generator. It is followed by the genitofemoral nerve, and iliohypogastric nerve. So far, several

\footnotetext{
* Correspondence: Iljnj2013@163.com

${ }^{\dagger}$ Kamleshsingh Shadhu and Dadhija Ramlagun contributed equally to this work.

Department of General Surgery, Jiangsu Province Hospital and The First Affiliated Hospital of Nanjing Medical University, Guangzhou road, 300, Gulou district, Nanjing, Jiangsu 210029, People's Republic of China
}

treatment regimens have been proposed, although high level evidence is scarce [8]. We report a case of a patient with sensory disturbances with acute, unbearable and disabling pain in the right lower limb for 1 month after a right inguinal hernioplasty.

\section{Case presentation}

A 54-year-old male patient presented with post-operative pain for 1 month. He underwent right inguinal hernioplasty 1 month ago at a different hospital. The patient complained about pain, of score 9 (on a scale of 1-10; 1 being normal 10 being most severe), around the right medial thigh and the pain intensified when he stands or walks for a long time and complains about abnormal walking posture. This situation was accompanied by lateral hip joint pain: the hip joint was unable to adduct and sometimes the pain can be felt at the knee joint if severe enough. It was also accompanied by pain during micturition which however, was relieved after rest. The CT scan showed bilateral hip joint degenerative changes, oedema at the region of the right inguinal hernioplasty and encapsulated effusion at the right pelvic cavity (Fig. 1). He was diagnosed with neuralgia after right inguinal hernioplasty. When he was admitted to our hospital, local anaesthetics were used at two points: one just above the right pubic tubercle and the other 2 fingers

(c) The Author(s). 2018 Open Access This article is distributed under the terms of the Creative Commons Attribution 4.0 International License (http://creativecommons.org/licenses/by/4.0/), which permits unrestricted use, distribution, and 


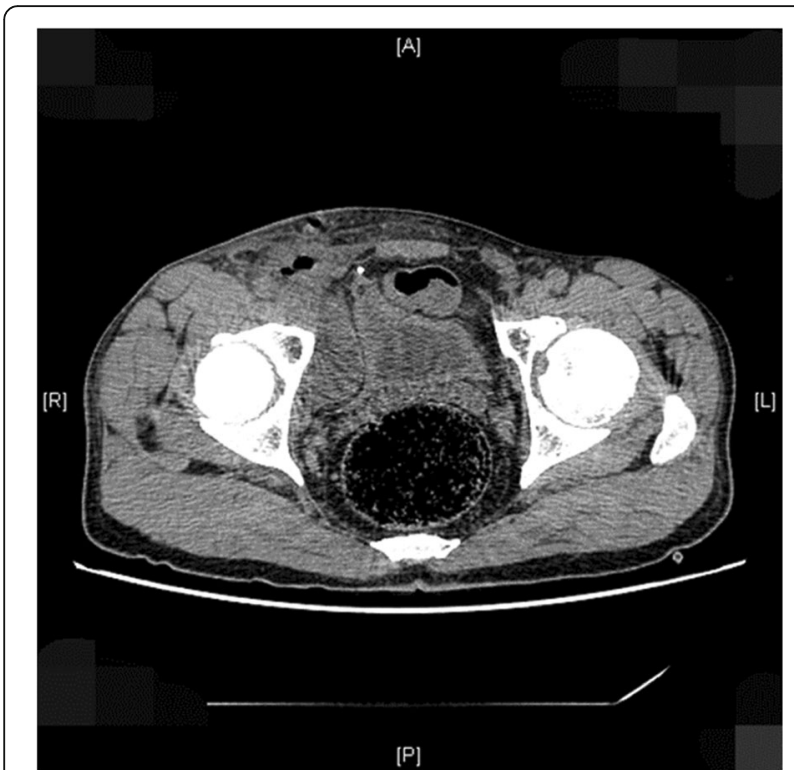

Fig. 1 CT scan of the patient

above the right inguinal ligament and medial to the right anterior superior iliac spine. The pain was alleviated temporarily for just 2 hours. Conservative regimen which included pain killer Tramadol failed. He underwent partial neurectomy under general anaesthesia based on his right to autonomy. During the surgery, the spermatic cord was freed, and the mesh was visible. Modified Kugel mesh procedure was carried out in the previous surgery during which 4 sutures over the transversalis fascia were stitched. The mesh had adhesion with the surrounding tissues, with unclear boundaries. The mesh was exposed and right iliohypogastric nerve was observed on the superficial surface of the mesh. The right iliohypogastric injury was due to entrapment from 3 sutures and the 'Kugel' mesh (Fig. 2). The genitofemoral nerve was explored for any abnormality. The nerves were identified based on their courses. The 4 non-absorbable sutures were all removed since the mesh has been integrated to the surrounding tissues. Tailored neurectomy of the iliohypogastric nerve was carried out whereby $3.5 \mathrm{~cm}$ of nerve length was resected. The proximal ends were cauterized. On POD 1 the patient stated that the pain was relieved and restored to ambulation and he had no pain during micturition either. He was discharged on POD 3. There has been no further complaints or abnormalities from this patient during follow-ups.

\section{Discussion \& Conclusion}

The surgical approach for neurectomy is still a controversial issue. The traditional anterior approach to the ilioinguinal and iliohypogastric nerves [9], has been reported to have success rates between 30 and 100\% [10, 11]. Surgery as an option for treating nerve-associated

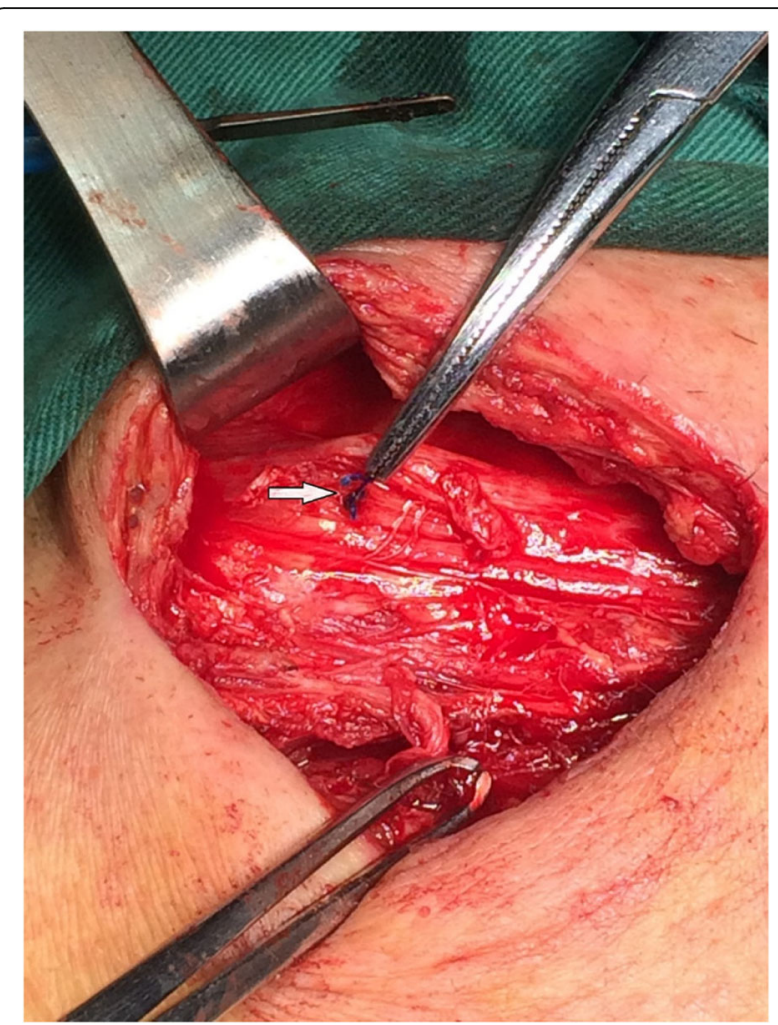

Fig. 2 White arrow showing the iliohypogastric nerve entrapment from sutures and the 'Kugel' mesh, found during the surgery

pain was described by Stulz and Pfeiffer, in 1982 [12]. Cicatricotomy to treat inguinal neuralgia after inguinal herniotomy, appendicectomy, and gynecological operations, was performed by them. Surgical neurectomy is the optimum method of treatment when conservative treatment has failed, and it was postulated that ilioinguinal nerve is the most endangered after hernia surgeries $[5,10,11,13]$. This shows that our case is even rarer due to the involvement of iliohypogastric nerve. Moreover, Vuilleumier used an open approach to perform a radical ilioinguinal nerve and iliohypogastric nerve neurectomy without routinely dissecting the genitofemoral nerve, having $95 \%$ pain relief in 49 patients [11]. Some authors found beneficial results resecting only the specific nerves that fit the clinical pain syndrome- 'tailored neurectomy' [13]. In addition, the use of cross-sectional computed tomography (CT) has been advocated to exclude recurrence or meshoma and investigate other differential diagnoses of chronic postoperative inguinal pain [14]. This explains the use of CT scan as imaging modality in our case.

Up to now there has been no specific guidelines about the treatment of this clinical entity and surgical neurectomy has proved to be the most effective treatment modality. 
We, therefore, reported this case to increase awareness among clinicians and stress on the importance of the identification of iliohypogastric nerve in open hernioplasty. However, our limitation is that it is a single case experience and conclusion can only be drawn based on our experience.

\section{Abbreviations}

CT: Computed Tomography; POD: Post-Operative day

\section{Author's contribution}

$\mathrm{KS}, \mathrm{DR}$, SC and LL all have made substantial contributions to conception, acquisition of data, analysis, and interpretation of data. All of them have been involved in drafting the manuscript and revising it critically for important intellectual content. All authors read and approved the final manuscript and take public responsibility for appropriate portions of the content and agreed to be accountable for all aspects of work.

\section{Funding}

This case report did not receive any specific grant from funding agencies in the public, commercial, or not-for-profit sectors.

\section{Ethics approval and consent to participate}

Not applicable.

\section{Consent for publication}

Written informed consent was obtained from the participants for publication of this article and any accompanying tables/images. A copy of the written consent is available for review by the Editor of this journal.

\section{Competing interests}

The authors declare no competing interests.

\section{Publisher's Note}

Springer Nature remains neutral with regard to jurisdictional claims in published maps and institutional affiliations.

Received: 2 February 2018 Accepted: 6 August 2018

Published online: 16 August 2018

\section{References}

1. Birk, D., ., S. Hess, ., and C. Garcia-Pardo, . Low recurrence rate and low chronic pain associated with inguinal hernia repair by laparoscopic placement of Parietex ProGrip? Mesh: clinical outcomes of 220 hernias with mean follow-up at 23 months. Hernia, 2013. 17(3): p. 313-320.

2. Nienhuijs SW, Boelens OB, Strobbe LJ. Pain after anterior mesh hernia repair J Am Coll Surg. 2005;200(6):885-9.

3. Loos MJ, Roumen RM, Scheltinga MR. Chronic sequelae of common elective groin hernia repair. Hernia. 2007;11(2):169-73.

4. Poobalan AS, et al. A review of chronic pain after inguinal herniorrhaphy. Clin J Pain. 2003;19(1):48-54.

5. Zacest $\mathrm{AC}$, et al. Long-term outcome following ilioinguinal neurectomy for chronic pain. J Neurosurg. 2010;112(4):784-9.

6. Aasvang $\mathrm{E}$, Kehlet $\mathrm{H}$. Surgical management of chronic pain after inguinal hernia repair. Br J Surg. 2005;92(7):795-801.

7. Baynielsen $\mathrm{M}$, et al. Chronic pain after open mesh and sutured repair of indirect inguinal hernia in young males. Br J Surg. 2004;91(10):1372-6.

8. Alfieri $\mathrm{S}$, et al. International guidelines for prevention and management of post-operative chronic pain following inguinal hernia surgery. Hernia. 2011; 15(3):239.

9. Amid PK. Causes, prevention, and surgical treatment of postherniorrhaphy neuropathic inguinodynia: triple neurectomy with proximal end implantation. Hernia. 2004:8(4):343-9.

10. Valvekens $E$, Nijs Y, Miserez M. Long-term outcome of surgical treatment of chronic postoperative groin pain: a word of caution. Hernia. 2015;19(4): 587-94.

11. Vuilleumier H, Hübner M, Demartines N. Neuropathy after Herniorrhaphy: indication for surgical treatment and outcome. World J Surg. 2009;33(4):841.
12. Stulz $P$, Pfeiffer KM. Peripheral nerve injuries resulting from common surgical procedures in the lower portion of the abdomen. Arch Surg. 1982; 117(3):324.

13. Loos MJ, Scheltinga MR, Roumen RM. Tailored neurectomy for treatment of postherniorrhaphy inguinal neuralgia. Surgery. 2010;147(2):275-81.

14. Ferzli GS, Edwards ED, Khoury GE. Chronic pain after inguinal herniorrhaphy. J Am Coll Surg. 2007;205(2):333.

\section{Ready to submit your research? Choose BMC and benefit from:}

- fast, convenient online submission

- thorough peer review by experienced researchers in your field

- rapid publication on acceptance

- support for research data, including large and complex data types

- gold Open Access which fosters wider collaboration and increased citations

- maximum visibility for your research: over $100 \mathrm{M}$ website views per year

At $\mathrm{BMC}$, research is always in progress.

Learn more biomedcentral.com/submissions 